\title{
Melatonin and Diazepam Affect Anxiety-Like and Depression-Like Behavior in Wistar Rats: Possible Interaction with Central GABA Neurotransmission
}

\author{
Sihame Ouakki ${ }^{1}$, Fatima Zahra El Mrabet ${ }^{1 *}$, Ibtissam Lagbouri ${ }^{1}$, Aboubaker El Hessni ${ }^{1}$, \\ Abdelhalem Mesfioui ${ }^{1}$, Paul Pévet ${ }^{2}$, Etienne Challet $^{2}$, Ali Ouichou ${ }^{1}$ \\ ${ }^{1}$ Unit of Nervous and Endocrine Physiology, Laboratory of Genetics, Neuroendocrinology and Biotechnology, \\ University Ibn Tofail, Kenitra, Morocco \\ ${ }^{2}$ Institute for Cellular and Integrative Neurosciences, UPR 3212 CNRS, University of Strasbourg, Strasbourg, France \\ Email:*fatimaa93@hotmail.com,ouichou@hotmail.com
}

Received August 21, 2013; revised September 25, 2013; accepted October 5, 2013

Copyright (C) 2013 Sihame Ouakki et al. This is an open access article distributed under the Creative Commons Attribution License, which permits unrestricted use, distribution, and reproduction in any medium, provided the original work is properly cited.

\begin{abstract}
Recent studies have shown the importance of the GABA-ergic transmission in the pathophysiology of anxiety and depressive disorders in humans. Our present study aims to investigate the interaction of melatonin (MEL) with this system by exploring the effects of MEL with or without a facilitator of GABA-ergic neurotransmission, diazepam (DZ) on the levels of depression and anxiety in Wistar rats. For this purpose, different doses of MEL (2, $4 \mathrm{or} 16 \mathrm{mg} / \mathrm{kg})$ or DZ (2 $\mathrm{mg} / \mathrm{kg}$ ) are subchronically administered during 15 days. After pharmacological treatments, anxiety levels are evaluated in behavioral tests of Open Field (OFT) and elevated plus maze (EPM) and depression levels are evaluated by the forced swim test (FST). The results showed that MEL produces anxiolytic-like and antidepressant-like effects in a dosedependent manner; the maximum effect was obtained at a dose of $16 \mathrm{mg} / \mathrm{kg}$. However, a dose of $4 \mathrm{mg} / \mathrm{kg}$ is necessary to induce an effect. The effect of MEL and DZ reported in this study concerns selective modulation of behavioral anxiety and depression since locomotor activity assessed by the OFT and EPM was not affected. The subchronic injection of MEL at $4 \mathrm{mg} / \mathrm{kg}, \mathrm{DZ}$ at $2 \mathrm{mg} / \mathrm{kg}$ or the two combined molecules also induces also anxiety-like and antidepressant-like behavior. In addition, a potentiating effect between MEL and DZ was observed. These effects suggest that psychopharmacological actions of MEL are due, at least in part, to its ability to improve the central GABA-ergic transmission.
\end{abstract}

Keywords: Melatonin; Diazepam; Depression; Anxiety; Open Field; Elevated plus Maze; Forced Swimming Test; Rat

\section{Introduction}

Melatonin (MEL) is synthesized primarily in the pin- eal gland and retina, since the pinealectomy abolishes its synthesis and suppresses endogenous rhythm of its secretion in all mammals [1].

The MEL synthesis in pinealocytes depends on the availability of its precursor, L-tryptophan (L-TRP) an essential amino acid. The first step of the biosynthesis of this indolamine involves L-TRP absorption into pinealocytes and its conversion to 5-hydroxytryptophan (5HTRP) by the TRP-hydroxylase. Decarboxylation of 5HTRP by L-aromatic decarboxylase leads to the formation of 5-hydroxytryptamine or serotonin (5-HT). Then,

${ }^{*}$ Corresponding author. acetylation of 5-HT by arylalkylamine $\mathrm{N}$-acetyltransferase (AA-NAT) leads to the formation of $\mathrm{N}$-acetylserotonin (NAS) [2]. Finally, methylation of NAS by hydroxyindole-O-methyltransferase (HIOMT) leads to the synthesis of the final product, the MEL. Once synthesized, the pineal hormone can easily cross the blood-brain barrier to enter the central nervous system [3].

Physiological, pharmacological and behavioral properties of MEL have been widely studied. The main function of MEL is to synchronize circadian rhythms [4] and organize several seasonal rhythms [5]. In humans, disruption of these rhythms is often associated with seasonal and non-seasonal affective disorders which characterized by disturbances in MEL secretion pattern. Most studies reveal a reduction in circulating levels means MEL ("low 
melatonin syndrome"), particularly in unipolar or bipolar affective disorders, and as such seems to be a good marker transnosographic depressive disorder. A similar reduction of nocturnal MEL rate is observed in panic disorder [6]. Paradoxically, McIntyre et al., [7] have reported abnormally high levels of MEL in depressed patients compared to healthy subjects, and Bandelow et al. [8] showed MEL levels comparable to those of healthy subjects in panic disorders.

In rodents, preclinical studies have shown that MEL exercised antidepressant-like and anxiolytic-like in animal models of anxiety, such as passive avoidance test, OFT and EPM tests, and light/dark box, such tests known for their ability to cause anxiety under presence of aversive stimuli [9-11]. Recently, we reported in two separate studies that: 1) chronic administration of MEL induced anxiolytic-like effect in OFT and EPM paradigms and antidepressant-like effect in FST test, such effects were depending on sex hormones [12] and 2) suppression of the synthesis of endogenous MEL by pinealectomy increases levels of anxiety-like and depression-like, confirming the anxiolytic-like and antidepressant-like nature of MEL [13]. Kopp et al. [11] have also shown that MT1/MT2 receptors agonist (S 23478) were effective in the free exploration test and light/dark box, whereas MT3 receptor agonists are less or not effective under the same experimental conditions [11].

Moreover, GABA-ergic neurotransmission system plays an important role in the regulation of anxiety and depressive behavioral disorders [14]. GABA-ergic theory of depression raised in the 1990s [15] is based on several experimental facts especially decrease in GABA plasma and GAD67 cerebral levels, enzyme involved in GABA synthesis from glutamate in depressed patients. Similar GABA-ergic plasma and cerebrospinal deficit are reported in some mood disorders in patients with depression [16]. In patients with panic disorder, similar observations were reported in the hippocampus, parahippocampus and orbitofrontal cortex. Recent studies have confirmed the importance of GABA (GABA-A and GABA-B) in depression, suggesting that neurophysiological deficit of GABA receptors is linked to the pathophysiology of mood disorders such as major depressive disorder $[17,18]$. Clinical trials have shown that mixed GABA mimetics, acting on both GABA-A and GABA-B receptors, have similar efficacy than conventional antidepressants in humans [19-22]. Both compounds were also active in standard animal models of depression, such as olfactory bulbectomy or learned helplessness $[23,24]$. Benzodiazepines (BZD) appear to act on areas of the limbic system, the thalamus and the hypothalamus to induce anxiolytic effects.

Some studies reported the existence of reciprocal effects between MEL and BZD. MEL seems to reduce de- pendence and tolerance caused by chronic use of BZD [25]. Many observations seem to support this direction: 1) BZD binding sites were identified in the pineal gland and in the rat removal of the gland abolishes the diurnal variation of BZD binding sites in the cerebral cortex; 2) in humans BZD may potentiate inhibitory effect of GABA on MEL synthesis, which in turn induces changes in function of GABA receptors and BZD; and 3) in vivo, diazepam (DZ) induces strong inhibition of MEL production, by acting directly on AA-NAT, limiting factor of MEL synthesis [26,27]. Furthermore, in rats, chronic treatment with DZ causes the disappearance of MEL binding sites in the "pons medulla". More interesting is that exogenous MEL increases the BZD binding in this brain region and cancels the deletion of MEL binding sites caused by DZ [25]. The existence of interaction between MEL and some BZD is extended to the regulation of mood, since MEL enhances the effect of DZ on anxiety levels [28], alters the effects of cocaine in the nucleus accumbens [29] and its effect on anxiety is inhibited by Fumazenil, GABA-ergic antagonist [30,31]. All these reciprocal effects between MEL and BZD suggest that psychopharmacological actions of MEL are due, at least in part to its ability to improve the central GABA-ergic transmission $[32,33]$.

The study of the interaction between MEL and DZ effects on anxiety-like and depressive-like behaviors can be interesting because it will show a possible interaction of the pineal hormone with the GABA-ergic system and therefore help to understand MEL action mechanisms. For this purpose, we undertake 1) to examine the effect of different doses of chronic MEL administration (2, 4 and $16 \mathrm{mg} / \mathrm{kg}$ ) on anxiety-like and depression-like levels and 2) to explore the effect of anxiolytic-like effect of 2 $\mathrm{mg} / \mathrm{kg}$ of DZ alone or in combination with $4 \mathrm{mg} / \mathrm{Kg}$ of MEL on anxiety-like and depression-like levels in wistar rats. This study will be possible by use of validated behavioral tests in rodents, namely OFT and EPM for anxiety-like and FST for despair-like levels.

\section{Material and Methods}

\subsection{Animals}

This experimental study was performed on female Wistar rats initially weighing $(120 \pm 20) \mathrm{g}$. Animals, from breeding of Faculty of life sciences, University Ibn Tofaïl, were housed by six in cages $(36 \mathrm{~cm}$ long, $20 \mathrm{~cm}$ wide and $15 \mathrm{~cm}$ high). All rats were maintained under LD 12/ 12 (12 h Light/12 h Darkness) and at a standard temperature $(21 \pm 1)^{\circ} \mathrm{C}$. Water and food were provided ad libitum. At the beginning of experiments, the colony room was maintained under a long photoperiod LD: 16/8 (16 h Light/8 h Darkness). 


\subsection{Drugs}

MEL was obtained from Sigma (France Lot. 112K0998) and DZ (Diapharm) from Pharma Laboratories 5/J. (Morocco). The control group was treated with saline $\mathrm{NaCl}$ $(0.9 \%)$ containing $5 \%$ ethanol and treated groups receive the MEL or DZ dissolved in $\mathrm{NaCl}(0.9 \%)$ also containing $5 \%$ ethanol. To consider body weight evolution, injected volumes are adjusted twice a week on body growth of animals.

\subsection{Pharmacological Treatments}

\section{- Effects of different doses of MEL:}

This experiment aims to investigate the anxiolytic-like and antidepressant-like effects of MEL in comparison with a control group treated with saline solution. For this purpose, animals were divided into 4 groups of 6 animals as following: (group 1: control): rats injected subcutaneously, once daily with saline solution $\mathrm{NaCl}(0.9 \%)$ as vehicle containing 5\% ethanol, (group 2: MEL2): rats injected with $2 \mathrm{mg} / \mathrm{kg}$ of MEL (group 3: MEL4): rats injected with $4 \mathrm{mg} / \mathrm{kg}$ of MEL and (group 4: MEL16): rats injected with $16 \mathrm{mg} / \mathrm{kg}$ of MEL. All injections were made approximately at 4:00 pm ( $2 \mathrm{~h}$ before dark phase) during 15 days.

\section{- Combined effects of MEL and DZ:}

This experiment was used to study the effects of the pineal hormone in combination with DZ. Animals were divided into 4 groups of 6 animals as following: (group 1: control): rats injected subcutaneously, once daily with saline solution $\mathrm{NaCl}(0.9 \%)$ as vehicle containing $5 \%$ ethanol, (group 2: MEL4): rats injected with $4 \mathrm{mg} / \mathrm{Kg}$ of MEL (group 3: DZ2): rats injected with $2 \mathrm{mg} / \mathrm{Kg}$ of DZ and (group 4: MEL4 + DZ2): rats injected simultaneously with $4 \mathrm{mg} / \mathrm{kg}$ MEL and $2 \mathrm{mg} / \mathrm{Kg} \mathrm{DZ}$. All injections were made approximately at 4:00 pm ( $2 \mathrm{~h}$ before dark phase) during 15 days.

\subsection{Anxiety-Like Measurement}

\section{- Open Field Test:}

The OFT is used to measure the anxiety-like behavior in rodents [34,35]. The maze adopted is made of wood $(100 \mathrm{~cm} \times 100 \mathrm{~cm})$ enclosed with $40 \mathrm{~cm}$ high walls and placed under strong illumination $(100 \mathrm{~W}, 2 \mathrm{~m}$ above the apparatus). The area was divided into 25 squares $(20 \mathrm{~cm}$ $\times 20 \mathrm{~cm}$ ), defined as 9 central and 16 peripheral squares. At the beginning of the 10 -min test, the animal was placed in the centre of the apparatus and its behavior was videotaped for subsequent analysis. The quantified parameters were the time spent in the center of the area (TCA) and the number of returns to the center (NRC). Central perimeter residence time is used as a measure of anxiety. The number of returns to the central area is also an indicator of the emotional reactivity. The central area of a novel environment is anxiogenic and aversive and the behavioral inhibition appears therefore as an avoidance behavior towards the central zone of the OFT. Locomotors activity is represented by number of total squares (NTS). The apparatus was cleaned between each examination using $70 \%$ ethyl alcohol.

\section{- Elevated Plus-Maze Test:}

The EPM is an ethological model of anxiety in rodents provoked by the novelty and repulsion as a result of elevation and illumination of the maze [36,37]. This test is based on the creation of a conflict between the exploratory drive of the rat and its innate fear of open and exposed areas; it has been validated for the detection of emotional responses to anxiogenic and anxiolytic substances. Thus, increased open-arms exploration indicates reduced anxiety-related behavior. The EPM consists of a wooden plus-shaped platform elevated $70 \mathrm{~cm}$ above the floor. Two of the opposing arms $(50 \mathrm{~cm} \times 10 \mathrm{~cm})$ are closed by $40 \mathrm{~cm}$ high side and end walls, having an open roof. In order to avoid fall, the other two arms (open arms) were surrounded by $0.5 \mathrm{~cm}$ high edge, the four arms had at their intersection a central platform $(10 \mathrm{~cm} \times$ $10 \mathrm{~cm})$. A 100-W lamp was placed exactly over the central platform. At the beginning of the test, the rats were placed on the central area of the maze facing an open arm. The following parameters of anxiety-related behavior were measured during the 5 min testing period: 1) entries into open arms (EOA), 2) time spent on the open arms (TOA), 3) and number of full entries into the arms (TAE). Decreased anxiety-like behavior is illustrated by a significant statistical increase of parameters in open arms (time and/or entries). The total number of the entries into all arms provides general hyperactivity. To eliminate any lingering olfactory cues, the apparatus was cleaned between each examination using 70\% ethyl alcohol.

\subsection{Depression-Like Measurement in Forced Swimming Test}

The FST is an excellent maze used to assess the depressive-like behavior $[38,39]$. Swimming sessions were conducted by placing the rat in individual glass cylinders (height $=50 \mathrm{~cm}$; diameter $=30 \mathrm{~cm}$ ) containing $30 \mathrm{~cm}$ of water at $\left(23^{\circ} \mathrm{C} \pm 2^{\circ} \mathrm{C}\right)$. During the session, rats were forced to swim for $5 \mathrm{~min}$ and the duration of immobility was measured. The latency to the first bout of immobility was also recorded starting immediately after placing the rats in the cylinder. A rat was judged immobile when it ceased all active behaviors (i.e. struggling, swimming and jumping) and remained passively floating or making minimal movements necessary to maintain the nostrils above water. High percent time floating is interpreted as an increased depressive-like response $[38,40]$. 


\subsection{Quantitative Presentation of the Results and Statistics}

The importance of behavioral responses of different experimental groups is determined by considering the control group in each experiment as the basal level (NB) number equal to $100 \%$. The effects of different treatments were then calculated relative to this baseline.

All data are expressed as the means \pm standard error of the means (S.E.M.). To determine the differences between experimental groups statistical analysis was performed by analysis of variance (ANOVA) 1st/2nd order followed by a post-hoc tests (Fisher LSD) or Student test " $t$ ". Differences were considered significant when $\mathrm{p}<$ 0.05 , very significant when $p<0.01$ and highly significant when $\mathrm{p}<0.001$.

\section{Results}

\subsection{Effects of MEL on Anxiety Level in Open Field Test}

- Time spent in the central area (TCA) (Table 1):

The results summarized in Table 1 show that MEL stimulates TCA in dose-dependent manner, since at doses of 4 and $16 \mathrm{mg} / \mathrm{kg}$ it increases the TCA in comparison with the control group ( $p<0.01$ and $p<0.001$ respectively), whereas at $2 \mathrm{mg} / \mathrm{kg}$ MEL was is ineffective ( $\mathrm{p}>$ $0.05)$. In addition, there is a statistically significant difference between the groups MEL2/MEL4, MEL2/MEL16 and MEL4/MEL16 ( $<<0.05, \mathrm{p}<0.001$ and $\mathrm{p}<0.001$ respectively). Similar results were obtained by considering the relative comparison (TCA\% NB) between treated
MEL groups and the control group. MEL induced an average increase of $31 \%, 57 \%$ and $124 \%$ respectively at doses of 2, 4 and $16 \mathrm{mg} / \mathrm{kg}$, respectively (Table 1).

- Number of returns to the center (NRC) (Table 1):

The dose-dependent effect of MEL is also observed with referring to NRC parameter (Table 1). At doses of 4 and $16 \mathrm{mg} / \mathrm{kg}$, MEL increases the NRC compared with the control group, while the dose of $2 \mathrm{mg} / \mathrm{kg}$ did not induce any significant change in this parameter $(\mathrm{p}<0.01, \mathrm{p}$ $<0.001$ and $\mathrm{p}>0.05)$. A statistically significant difference was observed between MEL2 and MEL16 ( $\mathrm{p}<$ 0.05 ). In contrast, no difference was noted between MEL2 and MEL4 or between MEL4 and MEL16 groups ( $p>0.05)$. Similar results were reported by considering the relative comparison (NRC \% NB) between treated MEL groups and the control group. Indeed, MEL induced an average increase of approximately 29\%, 54\% and $75 \%$ respectively at doses of 2,4 and $16 \mathrm{mg} / \mathrm{kg}$, respectively (Table 1).

\section{- Number of total squares (NTS) (Table 1):}

Unlike to TCA and NRC parameters, MEL did not affect significantly NTS parameter, whatever the dose considered $(p>0.05)$ (Table 1).

\subsection{Effect of MEL on Anxiety in Elevated plus Maze Test}

- $\quad$ Time spent in open arms (TOA) (Table 2):

The results summarized in Table 2 show that MEL stimulates TOA in dose-dependent manner, since at doses of 4 and $16 \mathrm{mg} / \mathrm{kg}$ it increases the TOA compared with the control group $(\mathrm{p}<0.001)$, whereas at $2 \mathrm{mg} / \mathrm{kg} \mathrm{MEL}$

Table 1. Behavioral performances of rats measured in OFT. TCA: Time spent in the central area expressed in seconds (s) or as \% of basal level (\% BL), NRC: Number of returns to central area expressed as arbitrary values or as \% of basal level (\% BL); NTS: Number of total squares expressed as arbitrary values or as \% of basal level (\% BL), after 15 days of treatment with $0.9 \%$ of $\mathrm{NaCl}$ (Control), $2 \mathrm{mg} / \mathrm{kg}$ (MEL2) $4 \mathrm{mg} / \mathrm{kg}$ (MEL4) or $16 \mathrm{mg} / \mathrm{Kg}$ (MEL16) of MEL. The results are represented as mean \pm SEM. The significance level is 0.05 . ${ }^{*} \mathrm{p}<0.05,{ }^{* *} \mathrm{p}<0.01,{ }^{* * *} \mathrm{p}<0.001$.

\begin{tabular}{|c|c|c|c|c|c|}
\hline & Control & MEL2 & MEL4 & MEL16 & Statistical analysis \\
\hline TCA (\% BL) & $\begin{array}{l}12.46 \pm 2.05 \\
100 \pm 16.49\end{array}$ & $\begin{array}{c}15.74 \pm 2.24 \\
131 \pm 9.14\end{array}$ & $\begin{array}{c}19.62 \pm 2.37 \\
157.46 \pm 19.07\end{array}$ & $27.94 \pm 3.72$ & $\begin{array}{c}\text { T/MEL2: } \mathrm{p}>0.05 \\
\text { T/MEL4: }{ }^{* *} \mathrm{p}<0.01 \\
\text { T/MEL16: }{ }^{* *} \mathrm{p}<0.001 \\
\text { MEL2/MEL4: }{ }^{*} \mathrm{p}<0.05 \\
\text { MEL2/MEL16: }{ }^{* * *} \mathrm{p}<0.001 \\
\text { MEL4/MEL16: }{ }^{* * *} \mathrm{p}<0.001\end{array}$ \\
\hline NRC (\% BL) & $100 \pm 20.49$ & $129.73 \pm 38.93$ & $154.05 \pm 24.55$ & $175.67 \pm 25.28$ & $\begin{array}{c}\text { T/MEL2: } \mathrm{p}>0.05 \\
\text { T/MEL4: }{ }^{* *} \mathrm{p}<0.01 \\
\text { T/MEL16: }{ }^{* *} \mathrm{p}<0.001 \\
\text { MEL2/MEL4: } \mathrm{p}>0.05 \\
\text { MEL2/MEL16: }{ }^{*} \mathrm{p}<0.05 \\
\text { MEL4/MEL16: } \mathrm{p}>0.05\end{array}$ \\
\hline NTS (\% BL) & $93 \pm 7.96$ & $89.6 \pm 13.22$ & $92.4 \pm 28.91$ & $87.6 \pm 6.54$ & $\begin{array}{c}\text { T/MEL2: } \mathrm{p}>0.05 \\
\text { T/MEL4: } \mathrm{p}>0.05 \\
\text { T/MEL16: } \mathrm{p}>0.05 \\
\text { MEL2/MEL4: } \mathrm{p}>0.05 \\
\text { MEL2/MEL16: } \mathrm{p}>0.05 \\
\text { MEL4/MEL16: } \mathrm{p}>0.05\end{array}$ \\
\hline
\end{tabular}


was not effective $(\mathrm{p}>0.05)$. In addition, there is a difference statistically significant between MEL2/MEL4, MEL2/MEL16 and MEL4/MEL16 groups ( $<<0.05$, $p<$ 0.001 and $p<0.001$ respectively). Similar results were observed when considering the relative comparison (TBO $\% \mathrm{NB}$ ) between treated MEL and control groups. Thus, MEL induced an average increase of $21 \%, 61 \%$ and $82 \%$ at doses of 2, 4 and $16 \mathrm{mg} / \mathrm{kg}$, respectively (Table 2).

\section{- Entries to open arms (EOA) (Table 2):}

The dose-dependent effect of MEL was also observed with reference to EOA parameter (Table 2). At doses of 4 and $16 \mathrm{mg} / \mathrm{kg}$, it increases the EOA in comparison with control group, while at dose of $2 \mathrm{mg} / \mathrm{kg}$ pineal hormone did not induce any significant change in this parameter $(\mathrm{p}$ $<0.01, \mathrm{p}<0.001 \mathrm{p}>0.05$ respectively). No statistically significant difference was observed with comparing different treated MEL $(p<0.05)$ groups. The relative comparison (EOA \% NB) between treated MEL and control groups shows that MEL induced an average increase of parameter EOA of approximately $44 \%, 56 \%$ and $72 \%$ at doses of 2, 4 and $16 \mathrm{mg} / \mathrm{kg}$, respectively (Table 2).
- Total entries in arms (TEA) (Table 2):

In contrast to TOA and EOA parameters, MEL was no significant effect on the TEA parameter, whatever the dose considered $(p>0.05)$ (Table 2).

\subsection{Effect of MEL on Depression-Like Level in Forced Swimming Test}

- Effect on immobility time (TIM) (Table 3):

In the FST, MEL significantly reduced TIM in dosedependent manner (Table 3). The differences between the effects MEL at 4 and $16 \mathrm{mg} / \mathrm{kg}$ doses and control group were highly significant ( $p<0.001$ and $p<0.001$ respectively), whereas at dose $2 \mathrm{mg} / \mathrm{Kg}$ MEL was not effective $(p>0.05)$. The relative comparison (TIM \% NB) between treated MEL and control groups shows that MEL induced a mean reduction TIM approximately of $25 \%, 35 \%$ and $23 \%$ at doses of 2,4 and $16 \mathrm{mg} / \mathrm{kg}$, respectively (Table 3). In addition, there is a difference statistically significant between MEL2/MEL4, MEL2/ MEL16 and MEL4/MEL16 groups $(\mathrm{p}<0.05, \mathrm{p}<0.001$

Table 2. Behavioral performances of rats measured in EPM. TOA: Time spent in the open arms expressed in seconds (s) or as $\%$ of basal level (\% BL); EOA: Number of entries to open arms expressed as arbitrary values or as \% of basal level (\% BL); TEA: Total entries in all arms expressed as arbitrary values or as \% of basal level (\% BL), after 15 days of treatment with $0.9 \%$ of $\mathrm{NaCl}$ (Control), $2 \mathrm{mg} / \mathrm{kg}$ (MEL2) $4 \mathrm{mg} / \mathrm{kg}$ (MEL4) or $16 \mathrm{mg} / \mathrm{Kg}$ (MEL16) of MEL. The results are represented as mean \pm SEM. The significance level is 0.05 . ${ }^{*} \mathrm{p}<0.05,{ }^{* *} \mathrm{p}<0.01,{ }^{* * *} \mathrm{p}<0.001$.

\begin{tabular}{|c|c|c|c|c|c|}
\hline & Control & MEL2 & MEL4 & MEL16 & Statistical analysis \\
\hline TOA (\% BL) & $\begin{array}{l}22.26 \pm 4.97 \\
100 \pm 22.34\end{array}$ & $\begin{array}{c}26.94 \pm 4.58 \\
121.02 \pm 20.60\end{array}$ & $\begin{array}{c}36.04 \pm 5.29 \\
161.90 \pm 23.78\end{array}$ & $\begin{array}{c}40.64 \pm 4.25 \\
182.57 \pm 19.10\end{array}$ & $\begin{array}{c}\text { T/MEL2: } \mathrm{p}>0.05 \\
\text { T/MEL4: }{ }^{* * *} \mathrm{p}<0.001 \\
\text { T/MEL16: }{ }^{* * *} \mathrm{p}<0.001 \\
\text { MEL2/MEL4: }{ }^{*} \mathrm{p}<0.05 \\
\text { MEL2/MEL16: }{ }^{* * *} \mathrm{p}<0.001 \\
\text { MEL4/MEL16: }{ }^{* * *} \mathrm{p}<0.001\end{array}$ \\
\hline $\operatorname{EOA~(\% ~BL)~}$ & $\begin{array}{c}5 \pm 1.58 \\
100 \pm 31.62\end{array}$ & $\begin{array}{c}7.2 \pm 1.48 \\
144 \pm 29.66\end{array}$ & $\begin{array}{c}7.8 \pm 0.83 \\
156 \pm 16.73\end{array}$ & $172 \pm 33.46$ & $\begin{array}{c}\text { T/MEL2: } \mathrm{p}>0.05 \\
\text { T/MEL4: }{ }^{* *} \mathrm{p}<0.01 \\
\text { T/MEL16: }{ }^{* * *} \mathrm{p}=0.001 \\
\text { MEL2/MEL4: } \mathrm{p}>0.05 \\
\text { MEL2/MEL16: } \mathrm{p}>0.05 \\
\text { MEL4/MEL16: } \mathrm{p}>0.05\end{array}$ \\
\hline TEA (\% BL) & $13.6 \pm 2.88$ & $14.2 \pm 5.54$ & $110.29 \pm 31.62$ & $89.70 \pm 30.04$ & $\begin{array}{c}\text { T/MEL2: } \mathrm{p}>0.05 \\
\text { T/MEL4: } \mathrm{p}>0.05 \\
\text { T/MEL16: } \mathrm{p}>0.05 \\
\text { MEL2/MEL4: } \mathrm{p}>0.05 \\
\text { MEL2/MEL16: } \mathrm{p}>0.05 \\
\text { MEL4/MEL16: } \mathrm{p}>0.05\end{array}$ \\
\hline
\end{tabular}

Table 3. Behavioral performances of rats measured in FST. TIM: immobility timeexpressed in seconds (s) or as \% of basal level (\% BL), after 15 days of treatment with $0.9 \%$ of $\mathrm{NaCl}$ (Control), $2 \mathrm{mg} / \mathrm{kg}$ (MEL2) $4 \mathrm{mg} / \mathrm{kg}$ (MEL4) or 16 mg/kg (MEL16) of MEL. The results are represented as mean \pm SEM. The significance level is 0.05 . ${ }^{*} \mathbf{p}<0.05,{ }^{* *} \mathbf{p}<0.01,{ }^{* * *} \mathbf{p}<$ 0.001.

\begin{tabular}{|c|c|c|c|c|c|}
\hline & Control & MEL2 & MEL4 & MEL16 & Statistical analysis \\
\hline TIM (\% BL) & $191.6 \pm 10.62$ & $\begin{array}{l}143.0 \pm 3.60 \\
74.63 \pm 1.88\end{array}$ & $123.4 \pm 10.16$ & $147.6 \pm 4.72$ & $\begin{array}{c}\text { T/MEL2: } \mathrm{p}>0.05 \\
\text { T/MEL4: }{ }^{* * *} \mathrm{p}<0.001 \\
\text { T/MEL16: }{ }^{* * *} \mathrm{p}<0.001 \\
\text { MEL2/MEL4: }{ }^{*} \mathrm{p}<0.05 \\
\text { MEL2/MEL16: }{ }^{* * *} \mathrm{p}<0.001 \\
\text { MEL4/MEL16: }{ }^{* * *} \mathrm{p}<0.001\end{array}$ \\
\hline
\end{tabular}


and $\mathrm{p}<0.001$ respectively).

\subsection{Effects of MEL and/or DZ on Anxiety Level in Open Field Test}

- Time spent in the central area (TCA) (Table 4):

The results summarized in Table IV show that TCA is increased by $4 \mathrm{mg} / \mathrm{kg}$ of MEL, $2 \mathrm{mg} / \mathrm{kg}$ of DZ and two associated molecules in comparison with the control group, the difference being highly significant $(\mathrm{p}<0.001)$. In addition, there is an interaction between DZ and MEL since the difference between MEL4 and MEL4 + DZ2 groups was statistically significant $(\mathrm{p}=0.01)$. However, no significant difference was found the DZ2 group was compared with on one hand MEL4 or a combination of two molecules on the other hand ( $p>0.05$ for comparison MEL4/DZ2 or DZ2/MEL4 + DZ2).

Similar results were obtained by considering the relative comparison (TCA\% NB) between treated and control groups. MEL, DZ and 2 associated molecules induced respectively an average increase of $47 \%, 57 \%$ and $75 \%$ (Table 4).

- Number of returns to the center (NRC) (Table 4):

As TCA, NRC parameter is also increased by the MEL, $\mathrm{DZ}$ and two associated molecules in comparison with the control group $(p<0.001)$ (Table 4). The effect induced by DZ and MEL is statistically higher when compared to MEL $(p<0.01)$ or to DZ $(p<0.05)$ treated groups. However, no significant difference was observed between MEL and DZ treated groups ( $p>0.05)$ groups. Similar results were obtained by referring to relative comparison
(NCC \% NB) between all treated and control groups. MEL, DZ and combined molecules produced an average enhancement of $74 \%, 91 \%$ and $131 \%$ respectively (Table 4).

- Number of total squares (NTS) (Table 4):

In contrast of TCA and NRC, MEL, DZ or 2 combined associated did not alter significantly NTS parameter ( $p>$ 0.05) (Table 4).

\subsection{Effect of MEL and/or DZ on Anxiety in Elevated plus Maze Test}

\section{- Time spent in open arms (TOA) (Table 5):}

MEL, DZ and the two associated molecules stimulated TOA in comparison with the control group $(\mathrm{p}<0.001)$ (Table 5). In addition, induced action of both $\mathrm{DZ}$ and MEL was statistically higher than that of MEL $(p<0.01)$. However, no significant difference was observed between the DZ and MEL or a combination of two molecules ( $p>0.05$ for comparison MEL4/DZ2 and DZ2/ MEL4 + DZ2). Comparable data are reported with reference to the relative comparison (TBO $\% \mathrm{NB}$ ) between treated and control groups. Indeed, MEL, DZ and 2 coadministrated substances caused an average augmentation of $47 \%, 57 \%$ and $75 \%$ (Table 5).

- Entries to open arms (EOA) (Table 5):

All treatment (MEL, DZ and DZ + MEL) caused a significant increase of EOA with comparison to the control group ( $p<0.05, p<0.01$ and $p<0.01$ respectively) (Table 5). In contrast, no significant difference was noted between MEL4/DZ2 MEL4/MEL4 + DZ2 or DZ2/MEL4

Table 4. Behavioral performances of rats measured in OFT. TCA: Time spent in the central area expressed in seconds (s) or as \% of basal level (\% BL), NRC: Number of returns to central area expressed as arbitrary values or as \% of basal level (\% BL); NTS: Number of total squares expressed as arbitrary values or as \% of basal level (\% BL), after 15 days of treatment with $0.9 \%$ of $\mathrm{NaCl}$ (Control), $4 \mathrm{mg} / \mathrm{kg}$ of MEL (MEL4), $2 \mathrm{mg} / \mathrm{kg}$ of DZ (DZ2) or simultaneously with $4 \mathrm{mg} / \mathrm{kg} \mathrm{of} \mathrm{MEL} \mathrm{and} 2$ $\mathrm{mg} / \mathrm{kg}$ of DZ (MEL4 + DZ2). The results are represented as mean \pm SEM. The significance level is $0.05 .{ }^{*} \mathrm{p}<0.05,{ }^{* *} \mathrm{p}<0.01$, p $<0.001$.

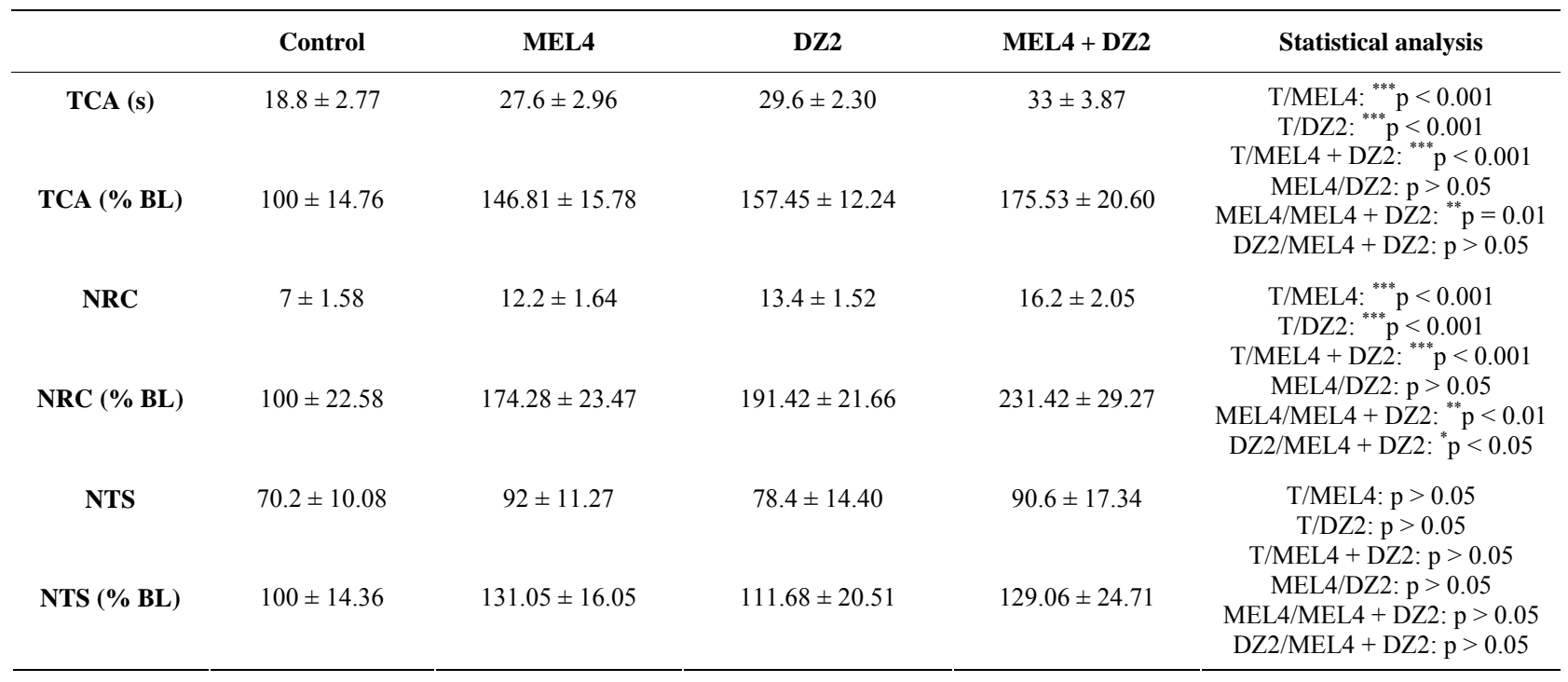


+ DZ2 groups $(\mathrm{p}>0.05)$. Comparable data were reported with reference to the relative comparison (EOA \% NB) between control and all treated groups. MEL, DZ and combined moleculesproduced anaverage enhancement of $33 \%, 40 \%$ and $48 \%$ (Table 5).

- Total entries in arms (TEA) (Table 2):

MEL, DZ or two associated substances prove unable to significantly affect TEA parameter $(\mathrm{p}>0.05)$ (Table $5)$.

\subsection{Effect of MEL and/or DZ on Depression-Like Level in Forced Swimming Test}

\section{- Effect on immobility time (TIM) (Table 6):}

In the FST, MEL, DZ and combined molecules strongly and significantly reduce the TIM $(\mathrm{p}<0.001)$ (Table 6). The relative comparison (TIM \% NB) between all treated control groups showed similar results. MEL, DZ and $(\mathrm{ML}+\mathrm{DZ})$ induced a mean reduction of TIM of $31 \%$, $62 \%$ and $66 \%$ respectively $(\mathrm{p}<0.001)$ (Table 6). DZ- or
$(\mathrm{MEL}+\mathrm{DZ})$-treated groups were statistically lower when compared to MEL treated group $(\mathrm{p}<0.001)$. In contrast, no significant difference was observed between DZ and $(\mathrm{MEL}+\mathrm{DZ})$ groups $(\mathrm{p}>0.05)$.

\section{Discussion}

The present study was designed to investigate: 1) the effects of different doses of MEL on anxiety-like and depression-like levels in rats and 2) the interaction of MEL with DZ, BZD known for its strong anxiolytic-like and antidepressant-like activities. Therefore, this could lead to the conclusion that there is a possible interaction between pineal hormone and GABA-ergic system. This study was conducted through the use of validated behavioral tests in rodents, especially OFT, EPM for anxiety levels and FST for depression level evaluation.

We have shown in this study that subchronic injection of MEL induced an anxiolytic-like effect in both OFT and EPM tests, since the animals of control group were

Table 5. Behavioral performances of rats measured in EPM. TOA: Time spent in the open arms expressed in seconds (s) or as $\%$ of basal level ( $\%$ BL); EOA: Number of entries to open arms expressed as arbitrary values or as \% of basal level (\% BL); TEA: Total entries in all arms expressed as arbitrary values or as \% of basal level (\% BL), after 15 days of treatment with $0.9 \%$ of $\mathrm{NaCl}$ (Control), $4 \mathrm{mg} / \mathrm{kg}$ of MEL (MEL4), $2 \mathrm{mg} / \mathrm{kg}$ of DZ (DZ2) or simultaneously with $4 \mathrm{mg} / \mathrm{kg}$ of MEL and $2 \mathrm{mg} / \mathrm{kg}$ of DZ (MEL4 + DZ2). The results are represented as mean \pm SEM. The significance level is $0.05 .{ }^{*} p<0.05,{ }^{* *} p<0.01,{ }^{* * * *} p<$ 0.001.

\begin{tabular}{|c|c|c|c|c|c|}
\hline & Control & MEL4 & DZ2 & MEL4 + DZ2 & Statistical analysis \\
\hline TOA (s) & $44.8 \pm 4.92$ & $65.2 \pm 6.83$ & $70.6 \pm 4.78$ & $78.6 \pm 7.70$ & $\begin{array}{c}\text { T/MEL4: }{ }^{* * *} \mathrm{p}<0.001 \\
\text { T/DZ2: }{ }^{* * *} \mathrm{p}<0.001 \\
\text { T/MEL4+DZ2: }{ }^{* * *} \mathrm{p}<0.001\end{array}$ \\
\hline TOA (\% BL) & $100 \pm 10.99$ & $145.53 \pm 15.25$ & $157.59 \pm 10.65$ & $175.45 \pm 17.19$ & $\begin{array}{c}\text { MEL4/DZ2: } \mathrm{p}>0.05 \\
\text { MEL4/MEL4 + DZ2: }{ }^{* *} \mathrm{p}<0.01 \\
\text { DZ2/MEL4 + DZ2: }>0.05\end{array}$ \\
\hline EOA & $5.4 \pm 1.14$ & $7.2 \pm 0.84$ & $7.6 \pm 1.14$ & $8 \pm 1.22$ & $\begin{array}{c}\text { T/MEL4: }{ }^{*} \mathrm{p}<0.05 \\
\text { T/DZ2: }{ }^{* *} p 0.01 \\
\text { T/MEL4 + DZ2: }{ }^{* *} \mathrm{p}<0.01\end{array}$ \\
\hline EOA (\% BL) & $100 \pm 21.11$ & $133.34 \pm 15.49$ & $140.74 \pm 21.23$ & $148.14 \pm 22.68$ & $\begin{array}{c}\text { MEL4/DZ2: } \mathrm{p}>0.05 \\
\text { MEL4/MEL4 + DZ2: } \mathrm{p}>0.05 \\
\text { DZ2/MEL4 + DZ2: }>0.05\end{array}$ \\
\hline TEA & $13.8 \pm 2.58$ & $14.2 \pm 3.11$ & $16 \pm 4.74$ & $14.8 \pm 5.89$ & $\begin{array}{l}\text { T/MEL4: } \mathrm{p}>0.05 \\
\text { T/DZ2: } \mathrm{p}>0.05\end{array}$ \\
\hline TEA (\% BL) & $100 \pm 18.75$ & $102.90 \pm 22.57$ & $115.94 \pm 34.37$ & $107.24 \pm 42.68$ & $\begin{array}{c}\text { T/MEL4 + DZ2: } \mathrm{p}>0.05 \\
\text { MEL4/DZ2: } \mathrm{p}>0.05 \\
\text { MEL4/MEL4 + DZ2: } \mathrm{p}>0.05 \\
\text { DZ2/MEL4 + DZ2: } \mathrm{p}>0.05\end{array}$ \\
\hline
\end{tabular}

Table 6. Behavioral performances of rats measured in FST. TIM: immobility time expressed in seconds (s) or as \% of basal level (\% BL), after 15 days of treatment with $0.9 \%$ of $\mathrm{NaCl}$ (Control), $4 \mathrm{mg} / \mathrm{kg}$ of MEL (MEL4), $2 \mathrm{mg} / \mathrm{kg} \mathrm{of} \mathrm{DZ} \mathrm{(DZ2)} \mathrm{or} \mathrm{si-}$ multaneously with $4 \mathrm{mg} / \mathrm{kg}$ of MEL and $2 \mathrm{mg} / \mathrm{kg}$ of DZ (MEL4 + DZ2). The results are represented as mean \pm SEM. The significance level is 0.05 . ${ }^{*}<0.05,{ }^{* *} \mathrm{p}<0.01,{ }^{* * *} \mathrm{p}<0.001$.

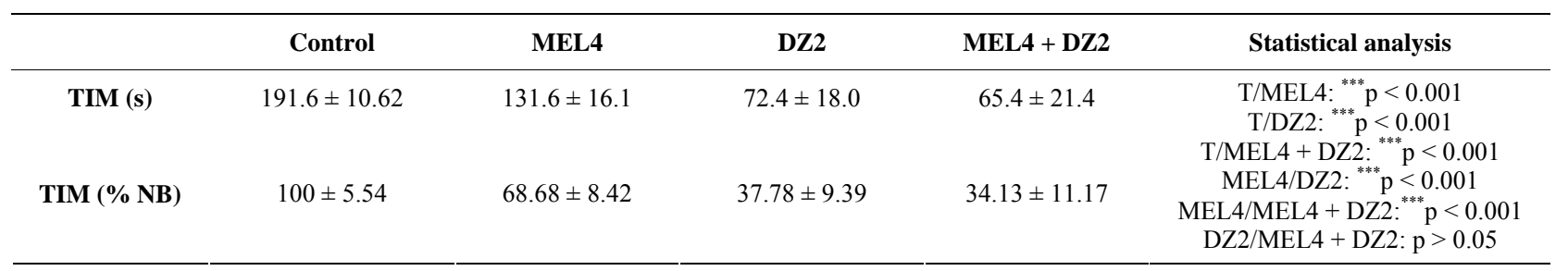


less mobile in the environment of the two paradigms anxiety. In addition, we have shown that this anxiolytic-like activity of MEL depends on the used dose of the pineal hormone, its effectiveness increasing with the concentration, since its effect is greater at $16 \mathrm{mg} / \mathrm{kg}$ than at $2 \mathrm{mg} /$ $\mathrm{kg}$. These results are entirely consistent with our previous observations showing that MEL caused an anxiolytic-like effect in rats [12,13]. Except study of Wong and Ong [41] in mice, showing that MEL was unable to produce any anxiolytic effectin OFT, majority, if not all other works have reported a significant reduction in anxiety behavior in animals treated with pharmacological doses of MEL, whatever the experimental conditions used or anxiogenic situations. Thus, in rats, it has been demonstrated that anxiolytic-like activity of MEL was higher than all tested other pineal indoles [37]. In the same species, anxiety-like behavior induced by microwave radiation is reduced by pretreatment with the MEL [42]. A reduction in the level of anxiety-like by pineal hormone has been also reported in Sprague Dawley rats genetically predisposed to show high anxiety behaviors, in hypertensive rats [43] and in $\mathrm{BALB} / \mathrm{c}$ and $\mathrm{C}_{3} \mathrm{H} / \mathrm{He}$ mice $[10,44]$. The effect of MEL is supported by the fact that hormone administration in the amygdala is followed by a decrease in the level of anxiety-like in both OFT and EPM [45]. Our results associated with the data mentioned above strongly corroborate that MEL has real anxiolytic-like properties.

We also showed in this study that rats treated with MEL showed lower levels of depression than control animals in the FST. In addition, we have clearly demonstrated that the antidepressant-like activity of MEL was dose-dependent, since TIM is greatly reduced at 16 $\mathrm{mg} / \mathrm{kg}$ than at $2 \mathrm{mg} / \mathrm{kg}$ dose. These results are in good agreement with data reported with our previous observations showing that chronic administration of MEL produced a real power antidepressant-like [12,13]. A similar reduction of swimming in the FST has been previously observed by Brotto et al. [46]. It was also reported that in rats subjected to this paradigm, low doses of MEL were able to reduce the TIM, confirming the antidepressantlike properties of pineal hormone [47]. In mice, despair index, as the coat state, grooming behavior and circulating corticosterone levels, observed after unpredictable chronic mild stress schedule, were reversed by daily administration of exogenous MEL or imipramine a tricyclic antidepressant drug [48]. In the same species, an enhancement of TIM reduction in the FST is obtained by co-administration of MEL and imipramine [49]. In rats and mice, MEL alone or combined with reserpine, an antidepressant binding to neurotransmitters vesicles as dopamine, norepinephrine, and serotonin significantly reduced the forced-swimming induced immobility period [50]. The antidepressant-like action of MEL was also obtained at pharmacological doses in transgenic mice
(BALB/c and C57BL/6J) [51]. Our results associated with these data strongly support that MEL has real antidepressantpotential.

The third finding concerns the potentiating of MEL effect by DZ, which is BZD characterized by strong anxiolytic-like and antidepressant-like activities [23,52]. Indeed, the anxiolytic-like and antidepressant-like effects induced by co-administration of MEL and DZ were significantly higher than those obtained with MEL or DZ injected separately. Our results were in accordance with numerous data reported in the literature. Thus, in mice, similar results were obtained by treatment with MEL alone or combined with DZ [14]. It is the same in the golden hamster since an anxiolytic-like effect of DZ was demonstrated in three experimental paradigms, EPM, the t-tube, and OFT of conflict Thatcher-Britton suggesting that the hamster such as rats and mice, is appropriate to evaluate the anxiolytic actions of drugs [52]. In the rats, using the punished drinking test, the safety signal withdrawal operant paradigm, the EPM and hypophagia-induced novelty, it has been shown that the MEL and agomelatine, a potent agonist of receptors MT(1/2), induce anxiolytic-like action, per se and can potentiate DZ effect [28]. An antistressor effect of MEL, more pronounced than that of DZ has also been shown in rats, such effect which was manifested by decreased anxiety, improved heart rhythm variability, and prevented stress-induced violation of circadian locomotion, suggesting that the differences may result from the expression of MEL chronotropic activity [53]. Modulation of the action of BZD by MEL has also been reported since MEL enhances the effect of DZ on anxiety levels [28], alters the effects of cocaine in the nucleus accumbens [29] and its effect on anxiety is inhibited by Fumazenil [30,31]. And still more convincing that intra-amygdal administration of MEL or DZ in rats caused a decrease in the level of anxiety in both OFT and EPM, DZ being more effective than MEL [45]. Our results in combination with all these studies strongly suggest that psychopharmacological effects of MEL are due, at least in part, to its ability to improve the central GABA-ergic transmission by modulating GABA receptors activity [32,33]. MEL appears therefore interact with the GABA-ergic system areas of the limbic system, including the amygdala, for regulating anxiety behavior.

This hypothesis is supported by the existence of receprocal effects of DZ and MEL on brain MEL and BZD binding sites. Thus, a significant increase in binding sites of GABA-BZD using ${ }^{3} \mathrm{H}-\mathrm{DZ}$ in rat brain has been reported in vivo by chronic injection of MEL. Similar results, in vitro, based on preincubation of synaptic membranes with MEL were reported by Coloma and Niles [54]. In humans, to insure its hypnotic function, it was suggested that MEL acts by increasing BZD receptor and 
the MEL itself and, therefore, strengthening the mechanisms inducing sleep. In rats, suppression of the diurnal variation of the BZD binding sites in the cerebral cortex has been described after experimental pinealectomy. Moreover, in rats, chronic treatment with DZ causes the loss of MEL binding sites in "pons medulla." More interesting is that exogenous MEL increases BZD binding in this brain region and reverses the suppression of MEL binding sites caused by DZ indicating that BZD-mediated suppression of brain melatonin binding sites can be abrogated by melatonin administration [25]. Djeridane and Touitou [26] showed that the inhibition of MEL production induced in vivo by $\mathrm{DZ}$ may be due to a direct action of this BZD on the NAT, the limiting factor of MEL synthesis. Such inhibitory effect has subsequently been considered independent of DZ metabolites [27]. Similar data, support the existence of interaction between MEL and BZD, has been reported in analgesic effect of MEL in young male ICR mice. These data indicate the synergistic analgesia effect of MEL with morphine and $\mathrm{DZ}$ and suggest the possible involvement of melatonin as an adjunct medicine for pain patients [55]. In addition, MEL, as an antioxidant inducing cell proliferation and DNA synthesis, may be useful in the fight against oxidative stress due to the long-term DZ administration [56].

However, research on the MEL regulation of behaviorral disorders allowed suggesting the implication of 5-HT and some of its receptors in mechanisms of MEL action. Indeed, it has been shown that MEL ligands as agomelatine (S20098) in FSL rats, and S20304 in transgenic mice have real antidepressant-like and anxiolytic-like properties [28,57]. As agomelatine is an agonist of MT1/2 receptor antagonist and a selective serotonin 5-HT $2 \mathrm{C}$ receptor, it was suggested that the activity of agomelatine is mediated byMT1/2 and/or 5-HT2C receptors [58]. Comparable results were obtained in mice using a MEL antagonist receptor luzindole $(\mathrm{N}-0774)$, suggesting that antidepressant activity of the ligand was mediated by antagonizing anxiogenic action of endogenous MEL [47, 59]. Finally, the antidepressant effect of MEL is completely inhibited by $5-\mathrm{HT} 2 \mathrm{~A} / 5-\mathrm{HT} 2 \mathrm{C}$ receptor agonists, suggesting the interaction of the pineal hormone with 5-HT neurotransmission [41,47].

\section{Conclusion}

Given the considerations mentioned above, without neglecting other mechanisms of action, our study suggests that the antidepressant-like and anxiolytic-like activities of MEL are mediated by an improvement of the GABAergic transmission. However, serotonergic noradrenergic and dopaminergic transmission may be involved in the expression of behavioral effects of MEL.

\section{Acknowledgements}

This work was supported by the project PROTARS (D14/03) between the University Ibn Toufail Kenitra and CNRST (Morocco), by GDRI Neurosciences (France, Morocco) and the European Neuromed project. Thank you to Professor P. Pévet, of the Institute of Cellular and Integrative Neurosciences, Department of Neurobiology of Rhythms, UPR-3212 CNRS, University of Strasbourg, France, for the gift of the MEL and for his support and encouragement.

\section{REFERENCES}

[1] R. A. Hoffman and R. J. Reiter, "Rapid Pinealectomy in Hamsters and Other Small Rodents," The Anatomical Record, Vol. 24, No. 1, 1965, pp. 83-89.

[2] H. Illnerova, J. Vaneek and K. Hoffmann, "Regulation of the Pineal Melatonin Concentration in the Rat (Rattus norvegicus) and the Djungarian hamster (Phodopus sungorus)," Comparative Biochemistry and Physiology, Vol. 74, No. 1, 1983, pp. 155-159.

http://dx.doi.org/10.1016/0300-9629(83)90727-2

[3] J. Leston, C. Harthé, J. Brun, C. Mottolese, P. Mertens, M. Sindou and B. Claustrat, "Melatonin Is Release in the Third Ventricle in Humans. A Study in Movement Disorders," Neuroscience Letters, Vol. 469, No. 3, 2009, pp. 294-297. http://dx.doi.org/10.1016/j.neulet.2009.12.008

[4] B. Claustrat, J. Brun and G. Chazot, "The Basic Physiology and Pathophysiology of Melatonin," Sleep Medicine Reviews, Vol. 9, No. 1, 2005, pp. 11-24. http://dx.doi.org/10.1016/j.smrv.2004.08.001

[5] P. Pevet, "The Role of the Pinealgland in the Photoperiodic Control of Reproduction in Different Hamster Species," Reproduction Nutrition Development, Vol. 28, No. 2B, 1988, pp. 443-458.

[6] R. Brown, J. H. Kocsis, S. Caroff, J. Amsterdam, A. Winokur, P. E. Stokes and A. Frazer, "Differences in Nocturnal Melatonin Secretion between Melancholic Depressed Patients and Control Subjects," American Journal of Psychiatry, Vol. 142, No. 7, 1985, pp. 811-816.

[7] I. M. McIntyre, T. R. Norman, G. D. Burrows and S. M. Armstrong, "Melatonin, Cortisol and Prolactin Response to Acute Nocturnal Light Exposure in Healthy Volunteers," Psychoneuroendocrinology, Vol. 17, No. 2-3, 1992, pp. 243-248.

http://dx.doi.org/10.1016/0306-4530(92)90063-D

[8] B. Bandelow, G. Sengos, D. Wedekind, G. Huether, J. Pilz, A. Broocks, G. Hajak and E. Ruther, "Urinary Excretion of Cortisol, Norepinephrine, Testosterone, and Melatonin in Panic Disorder," Pharmacopsychiatry, Vol. 30, No. 4, 1997, pp. 113-117. http://dx.doi.org/10.1055/s-2007-979494

[9] R. G. Lister, "Ethologically-Based Animal Models of Anxiety Disorders," Pharmacology \& Therapeutics, Vol. 46, No. 3, 1990, pp. 321-340. http://dx.doi.org/10.1016/0163-7258(90)90021-S

[10] C. Kopp, E. Vogel, M. C. Rettori, P. Delagrange, B. 
Guardiola-Lemaître and R. Misslin, "Effects of Melatonin on Neophobic Responses in Different Strains of Mice," Pharmacology Biochemistry and Behavior, Vol. 63, No. 4, 1999 , pp. 521-526.

http://dx.doi.org/10.1016/S0091-3057(99)00023-4

[11] C. Kopp, E. Vogel, M. C. Rettori, P. Delagrange and R. Misslin, "Anxiolytic-Like Properties of Melatonin Receptor Agonists in Mice: Involvement of Mt1 and/or MT2 Receptors in the Regulation of Emotional Responsiveness," Neuropharmacology, Vol. 39, No. 10, 2000, pp. $1865-1871$.

http://dx.doi.org/10.1016/S0028-3908(99)00263-4

[12] F. Z. El Mrabet, I. Lagbouri, A. Mesfioui, A. El Hessn and A. Ouichou, "The Influence of Gonadectomy on Anxiolytic and Antidepressant Effects of Melatonin in Male and Female Wistar Rats: A Possible Implication of Sex Hormones," Neuroscience \& Medicine, Vol. 3, No. 2, 2012, pp. 162-173.

[13] F. Z. El Mrabet, S. Ouakki, A. Mesfioui, A. El Hessni and A. Ouichou, "Pinealectomy and Exogenous Melatonin Regulate Anxiety-Like and Depressive-Like Behaviors in Male and Female Wistar Rats," Neuroscience \& Medicine, Vol. 3, 2012, pp. 394-403. http://dx.doi.org/10.4236/nm.2012.34049

[14] B. Guardiola-Lemaitre, A. Lenegre and R. D. Porsolt, "Combined Effects of Diazepam and Melatonin in Two Tests for Anxiolytic Activity in the Mouse," Pharmacology Biochemistry and Behavior, Vol. 41, No. 2, 1992, pp. 405-408.

http://dx.doi.org/10.1016/0091-3057(92)90118-Y

[15] A. Pilc and K. G. Lloyd, "Chronic Antidepressants and GABA "B" Receptors: A GABA Hypothesis of Antidepressant Drug Action," Life Sciences, Vol. 35, No. 21, 1984, pp. 2149-2154. http://dx.doi.org/10.1016/0024-3205(84)90515-0

[16] S. F. Kendell, J. H. Krystal and G. Sanacora, "GABA and Glutamate Systems as Therapeutic Targets in Depression and Mood Disorders," Expert Opinion on Therapeutic Targets, Vol. 9, No. 1, 2005, pp. 153-168. http://dx.doi.org/10.1517/14728222.9.1.153

[17] A. Guidotti, J. Auta, J. M. Davis, V. Di-Giorgi-Gerevini, Y. Dwivedi, D. R. Grayson, F. Impagnatiello, G. Pandey, C. Pesold, R. Sharma, D. Uzunov and E. Costa, "Decrease in Reelin and Glutamic Acid Decarboxylase67 (GAD67) Expression in Schizophrenia and Bipolar Disorder: A Postmortem Brain Study," Archives of General Psychiatry, Vol. 57, No. 11, 2000, pp. 1061-1069. http://dx.doi.org/10.1001/archpsyc.57.11.1061

[18] S. H. Fatemi, J. M. Stary, J. A. Earle, M. Araghi-Niknam and E. Eagan, "GABAergic Dysfunction in Schizophrenia and Mood Disorders as Reflected by Decreased Levels of Glutamic Acid Decarboxylase 65 and $67 \mathrm{kDa}$ and Reelin Proteins in Cerebellum," Schizophrenia Research, Vol. 72, No. 2-3, 2005, pp. 109-122. http://dx.doi.org/10.1016/j.schres.2004.02.017

[19] G. Bartholini, "Potential Therapeutic Activity of GABAMimetic Drugs in Neuropsychiatry," Schweizer Archiv für Neurologie, Neurochirurgie and Psychiatrie, Vol. 125, No. 2, 1979, pp. 265-269.

[20] G. Magni, M. Garreau, B. Orofiamma and R. Palminteri,
"Fengabine, a New GABAmimetic Agent in the Treatment of Depressive Disorders: An Overview of Six Double-Blind Studies versus Tricyclics," Neuropsychobiology, Vol. 20, No. 3, 1989, pp. 126-131.

http://dx.doi.org/10.1159/000118485

[21] N. P. Nielsen, B. Cesana, S. Zizolfi, V. Ascalone, P. Priore and P. L. Morselli, "Therapeutic Effects of Fengabine, a New GABAergic Agent, in Depressed Outpatients: A Doubleblind Study versus Clomipramine," Acta Psychiatrica Scandinavica, Vol. 82, No. 5, 1990, pp. 366-371. http://dx.doi.org/10.1111/j.1600-0447.1990.tb01402.x

[22] L. L. Carpenter, J. M. Schecter, A. R. Tyrka, A. F. Mello, M. F. Mello, R. Haggarty and L. H. Price, "Open-Label Tiagabine Monotherapy for Major Depressive Disorder with Anxiety," Journal of Clinical Psychiatry, Vol. 67, No. 1, 2006, pp. 66-71.

http://dx.doi.org/10.4088/JCP.v67n0110

[23] K. G. Lloyd, P. L. Morselli and G. Bartholini, "GABA and Affective Disorders," Medical Biology, Vol. 65, No. 2-3, 1987, pp. 159-165.

[24] K. G. Lloyd, B. Zivkovic, D. Sange, H. Depoortere and G. Bartholini, "Fengabine, a Novel Antidepressant GABAergic Agent. I. Activity in Models for Antidepressant Drugs and Psychopharmacological Profile," Journal of Pharmacology and Experimental Therapeutics, Vol. 242, No. 1, 1987, pp. 245-250.

[25] J. Atsmon, S. Oaknin, M. Laudon, S. Laschiner, M. Gavish, Y. Dagan and N. Zisapel, "Reciprocal Effects of Chronic Diazepam and Melatonin on Brain Melatonin and Benzodiazepine Binding Sites," Journal of Pineal Research, Vol. 20, No. 2, 1996, pp. 65-71. http://dx.doi.org/10.1111/j.1600-079X.1996.tb00241.x

[26] Y. Djeridane and Y. Touitou, "Chronic Diazepam Administration Differentially Affects Melatonin Synthesis in Rat Pineal and Harderian Glands," Psychopharmacology, Vol. 154, No. 4, 2001, pp. 403-407. http://dx.doi.org/10.1007/s002130000631

[27] Y. Djeridane and Y. Touitou, "Effects of Diazepam and Its Metabolites on Nocturnal Melatonin Secretion in the Rat Pineal and Harderian Glands. A Comparative in Vivo and in Vitro Study," Chronobiology International, Vol. 20, No. 2, 2003, pp. 285-297. http://dx.doi.org/10.1081/CBI-120018579

[28] F. Loiseau, C. Le Bihan, M. Hamon and M. H. Thiébot, "Effects of Melatonin and Agomelatine in Anxiety-Related Procedures in Rats: Interaction with Diazepam," European Neuropsychopharmacology, Vol. 16, No. 6, 2006, pp. 417-428.

http://dx.doi.org/10.1016/j.euroneuro.2005.11.007

[29] I. V. Zhdanova and M. Giorgetti, "Melatonin Alters Behavior and cAMP Levels in Nucleus Accumbens Induced by Cocaine Treatment," Brain Research, Vol. 956, No. 2, 2002, pp. 323-331. http://dx.doi.org/10.1016/S0006-8993(02)03565-5

[30] D. A. Golombek, M. Martini and D. P. Cardinali, "Melatonin as an Anxiolytic in Rats: Time Dependence and Interaction with the Central GABAergic System," European Journal of Pharmacology, Vol. 237, No. 2-3, 1993, pp. 231-236. 
http://dx.doi.org/10.1016/0014-2999(93)90273-K

[31] G. Pierrefiche, R. Zerbib and H. Laborit, "Anxiolytic Activity of Melatonin in Mice: Involvement of Benzodiazepine Receptors," Research Communications in Chemical Pathology and Pharmacology, Vol. 82, No. 2, 1993, pp. 131-142.

[32] L. P. Niles, D. S. Pickering and M. A. Arciszewski, "Effects of Chronic Melatonin Administration on GABA and Diazepam Binding in Rat Brain," Journal of Neural Transmission, Vol. 70, No. 1-2, 1987, pp. 117-124. http://dx.doi.org/10.1007/BF01252513

[33] L. P. Niles, O. M. Pulido and D. S. Pickering, "Age-Related Changes in GABA and Benzodiazepine Receptor Binding in Rat Brain Are Influenced by Sampling Time," Progress in Neuro-Psychopharmacology \& Biological Psychiatry, Vol. 12, No. 2-3, 1988, pp. 337-344. http://dx.doi.org/10.1016/0278-5846(88)90053-X

[34] C. Gentsch, M. Lichtsteiner and H. Feer, "Open Field and Elevated Plus-Maze: A Behavioural Comparison between Spontaneously Hypertensive (SHR) and Wistar-Kyoto (WKY) Rats and the Effects of Chlordiazepoxide," Behavioural Brain Research, Vol. 25, No. 2, 1987, pp. 101107. http://dx.doi.org/10.1016/0166-4328(87)90003-9

[35] V. Carola, F. D’Olimpio, E. Brunamonti, F. Mangia and P. Renzi, "Evaluation of the Elevated Plus-Maze and Open-Field Tests for the Assessment of Anxiety-Related Behaviour in Inbred Mice," Behavioural Brain Research, Vol. 134, No. 1-2, 2002, p. 49. http://dx.doi.org/10.1016/S0166-4328(01)00452-1

[36] S. K. Kulkarni and A. C. Sharma, "Elevated Plus-Maze: A Novel Psychobehavioral Tool to Measure Anxiety in Rodents," Methods and Findings in Experimental and Clinical Pharmacology, Vol. 13, No. 8, 1991, pp. 573577.

[37] E. B. Naranjo-Rodriguez, A. O. Osornio, E. HernandezAvitia, V. Mendoza-Fernandez and A. Escobar, "Anxiolytic-Like Actions of Melatonin, 5-Metoxytryptophol, 5Hydroxytryptophol and Benzodiazepines on a Conflict Procedure," Progress in Neuro-Psychopharmacology \& Biological Psychiatry, Vol. 24, No. 1, 2000, pp. 117-129. http://dx.doi.org/10.1016/S0278-5846(99)00075-5

[38] R. D. Porsolt, G. Anton, N. Blavet and M. Jalfre, "Behavioural Despair in Rats: A New Model Sensitive to Antidepressant Treatments," European Journal of Pharmacology, Vol. 47, No. 4, 1978, pp. 379-391. http://dx.doi.org/10.1016/0014-2999(78)90118-8

[39] N. Benabid and A. Ouichou, "Affective Responses of Early Life Photoperiod in Male Rats," Neurosciences and Medicine, Vol. 2, No. 3, 2011, pp. 185-191.

[40] N. Benabid, A. Mesfioui and A. Ouichou, "Effects of Photoperiod Regimen on Emotional Behaviour in Two Tests for Anxiolytic Activity in Wistar Rat," Brain Research Bulletin, Vol. 75, No. 1, 2008, pp. 53-59. http://dx.doi.org/10.1016/j.brainresbull.2007.07.016

[41] P. T.-H. Wong and Y. P. Ong, "Acute AntidepressantLike and Antianxiety-Like Effects of Tryptophan in Mice," Pharmacology, Vol. 62, 2001, pp. 151-156. http://dx.doi.org/10.1159/000056088

[42] D. Sokolovic, B. Djordjevic, G. Kocic, P. Babovic, G.
Ristic, Z. Stanojkovic, D. M. Sokolovic, A. Veljkovic, A. Jankovic and Z. Radovanovic, "The Effect of Melatonin on Body Mass and Behaviour of Rats during an Exposure to Microwave Radiation from Mobile Phone," Bratislavské Lekárske Listy, Vol. 113, No. 5, 2012, pp. $265-$ 269.

[43] L. Krsková, M. Vrabcová and M. Zeman, "Effect of Melatonin on Exploration and Anxiety in Normotensive and Hypertensive Rats with High Activity of Renin-Angiotensin System," Neuroendocrinology Letters, Vol. 28, No. 3, 2007, pp. 295-301.

[44] C. Kopp, E. Vogel, M. C. Rettori, P. Delagrange and R. Misslin, "The Effects of Melatonin on the Behavioural Disturbances Induced by Chronic Mild Stress in $\mathrm{C} 3 \mathrm{H} / \mathrm{He}$ Mice," Behavioural Pharmacology, Vol. 10, No. 1, 1999, pp. 73-83.

http://dx.doi.org/10.1097/00008877-199902000-00007

[45] A. Karakaş, H. Coşkun, A. Kaya, A. Kücük and B. Gündüz, "The Effects of the Intraamygdalar Melatonin Injections on the Anxiety Like Behavior and the Spatial Memory Performance in Male Wistar Rats," Behavioural Brain Research, Vol. 222, No. 1, 2011, pp. 141-150. http://dx.doi.org/10.1016/j.bbr.2011.03.029

[46] L. A. Brotto, A. M. Barr and B. B. Gorzalka, "Sex Differences in Forced-Swim and Open-Field Test Behaviours after Chronic Administration of Melatonin," European Journal of Pharmacology, Vol. 402, No. 1-2, 2000, pp. 87-93. http://dx.doi.org/10.1016/S0014-2999(00)00491-X

[47] V. Micale, A. Arezzi, L. Rampello and F. Drago, "Melatonin Affects the Immobility Time of Rats in the Forced Swim Test: The Role of Serotonin Neurotransmission," European Neuropsychopharmacology, Vol. 16, No. 7, 2006, pp. 538-545. http://dx.doi.org/10.1016/j.euroneuro.2006.01.005

[48] B. C. Detanico, A. L. Piato, J. J. Freitas, F. L. Lhullier, M. P. Hidalgo, W. Caumo and E. Elisabetsky, "Antidepressant-Like Effects of Melatonin in the Mouse Chronic Mild Stress Model," European Journal of Pharmacology, Vol. 607, No. 1-3, 2009, pp. 121-125. http://dx.doi.org/10.1016/j.ejphar.2009.02.037

[49] Y. Ergün, F. O. Orhan and M. F. Karaaslan, "Combination Therapy of Imipramine and Melatonin: Additive Antidepressant Effect in Mouse Forced Swimming Test," European Journal of Pharmacology, Vol. 591, No. 1-3, 2008, pp. 159-163. http://dx.doi.org/10.1016/j.ejphar.2008.06.070

[50] A. V. Shaji and S. K. Kulkarni, "Central Nervous System Depressant Activities of Melatonin in Rats and Mice," Indian Journal of Experimental Biology, Vol. 36, No. 3, 1998, pp. 257-263.

[51] V. Raghavendra, G. Kaur and S. K. Kulkarni, “Anti-Depressant Action of Melatonin in Chronic Forced Swimming-Induced Behavioral Despair in Mice, Role of Peripheral Benzodiazepine Receptor Modulation," European Neuropsychopharmacology, Vol. 10, No. 6, 2000, pp. 473-481.

http://dx.doi.org/10.1016/S0924-977X(00)00115-2

[52] R. L. Gannon, E. Lungwitz, N. Batista, I. Hester, C. Huntley, A. Peacock, P. Delagrange and M. J. Millan, 
"The Benzodiazepine Diazepam Demonstrates the Usefulness of Syrian Hamsters as a Model for Anxiety Testing: Evaluation of Other Classes of Anxiolytics in Comparison to Diazepam," Behavioural Brain Research, Vol. 218, No. 1, 2011, pp. 8-14. http://dx.doi.org/10.1016/j.bbr.2010.11.029

[53] E. B. Arushanian, E. V. Bě̌er and A. S. Bulgakova, "Pineal Melatonin Exhibits More Pronounced Antistressor Properties than Anxiolytic Diazepam," Eksperimental' naia i Klinicheskaia Farmakologiia, Vol. 70, No. 6, 2007, pp. 9-12.

[54] F. M. Coloma and L. P. Niles, "Melatonin Enhancement of [3H]-Gamma-Aminobutyric Acid and [3H] Muscimol Binding in Rat Brain," Biochemical Pharmacology, Vol. 37, No. 7, 1988, pp. 1271-1274. http://dx.doi.org/10.1016/0006-2952(88)90781-2

[55] C. S. Pang, S. F. Tsang and J. C. Yang, "Effects of Melatonin, Morphine and Diazepam on Formalin-Induced Nociception in Mice," Life Sciences, Vol. 68, No. 8, 2001, pp. 943-951.

http://dx.doi.org/10.1016/S0024-3205(00)00996-6
[56] G. H. El-Sokkary, "Melatonin and Vitamin C Administration Ameliorate Diazepam-Induced Oxidative Stress and Cell Proliferation in the Liver of Rats," Cell Proliferation, Vol. 41, No. 1, 2008, pp. 168-176.

http://dx.doi.org/10.1111/j.1365-2184.2007.00503.x

[57] D. H. Overstreet, O. Pucilowski, M. C. Retton, P. Delagrange and B. Guardiola-Lemaitre, "Effects of Melatonin Receptor Ligands on Swim Test Immobility," NeuroReport, Vol. 9, No. 2, 1998, pp. 429-453. http://dx.doi.org/10.1097/00001756-199801260-00014

[58] M. Bourin, E. Mocaër and R. Porsolt, “AntidepressantLike Activity of S 20098 (Agomelatine) in the Forced Swimming Test in Rodents: Involvement of Melatonin and Serotonin Receptors," Journal of Psychiatry and Neuroscience, Vol. 29, No. 2, 2004, pp. 126-133.

[59] M. L. Dubocovich, E. Mogilnicka and P. M. Areso, “Antidepressant-Like Activity of the Melatonin Receptor Antagonist, Luzindole (N-0774), in the Mouse Behavioral Despair Test," European Journal of Pharmacology, Vol. 182, No. 2, 1990, pp. 313-325.

http://dx.doi.org/10.1016/0014-2999(90)90290-M 